\title{
Integration of Intercultural Communicative Competence (ICC) in an EFL Course: Perceptions of Students and Teachers
}

\author{
Gökalp Güneş, Bahçeşehir University, ORCID ID: 0000-0003-3977-0937 \\ Enisa Mede, Bahçeşehir University, ORCID ID: 0000-0002-6555-5248
}

\begin{abstract}
While the use of appropriate linguistic features of the target language is essential for successful communication, sociocultural factors also play a crucial role. Intercultural communicative competence (ICC) is one dimension of sociocultural awareness that has been recognized as integral for communicative competence. However, the integration of ICC in second/foreign language classrooms remains a challenge, possibly due to the fact that language educators tend to have more knowledge about the target language than its related cultural aspects (CelceMurcia, 2007). This study, therefore, aims to find out the perceptions of students before and after integrating ICC in an elementary level English course. The study also attempts to reveal the reflections of the teacher offering this course about using ICC while teaching English. The participants were 20 Turkish EFL students and their teacher. The quantitative data were collected through pre-and post-ICC scale, while the qualitative data came from students' semi-structured interviews and teacher's reflective journals. The findings revealed that there were significant differences in the perceptions of the participants after the integration of ICC, which increased their awareness about different cultures, their own culture as well as the role of culture in language learning. Similarly, the teacher shared positive reflections about ICCdriven module in English classrooms apart from some difficulties experienced related to the speed of the videos and selected topics. The obtained findings offered pedagogical implications and suggestions about the inclusion of ICC in EFL classrooms.
\end{abstract}

Keywords: Intercultural communicative competence (ICC), learner's perceptions, teacher's reflection, ICC integration, EFL.
İnönü University

Journal of the Faculty of Education Vol 20, No 2, 2019

pp. 352-363

DOI: $10.17679 /$ inuefd.445793

Article type:

Research article

\section{Suggested Citation}

Güneş, G. and Mede, M. (2019). Integration of Intercultural Communicative Competence (ICC) in an EFL Course: Perceptions of Students and Teachers, Inonu University Journal of the Faculty of Education, 20(2), 352-363. DOI: 10.17679/inuefd. 445793 


\section{EXTENDED ABSTRACT}

\section{Introduction}

In the past few decades, the field of English Language Teaching (ELT) started to emphasize the linguistic and cultural diversity; rather than focusing only on teaching aspects related to the English language, ELT includes sociocultural factors addressing how language and culture are related to one's identity. Therefore, cultural awareness and intercultural communicative competence (ICC) have become an integral part of English classrooms. The need for cultural awareness cannot be ignored and in order to make communication sufficient, it needs to be accompanied by multidimensional cultural awareness since communication almost never exists culture-free. Specifically, culture and language have always been inseparable and closely bound together (Agar, 1994; Kramsch, 2000).

Weaver (1993), described culture with the iceberg theory. The external part of the iceberg such as art, literature, music, games, cooking can be seen or heard or touched and it represents explicitly learned culture whereas the internal part of the iceberg such as emotion, justice, modesty cannot be seen or heard or touched and it represents implicitly learned culture. Weaver's Iceberg Theory is as presented in Figure 1.

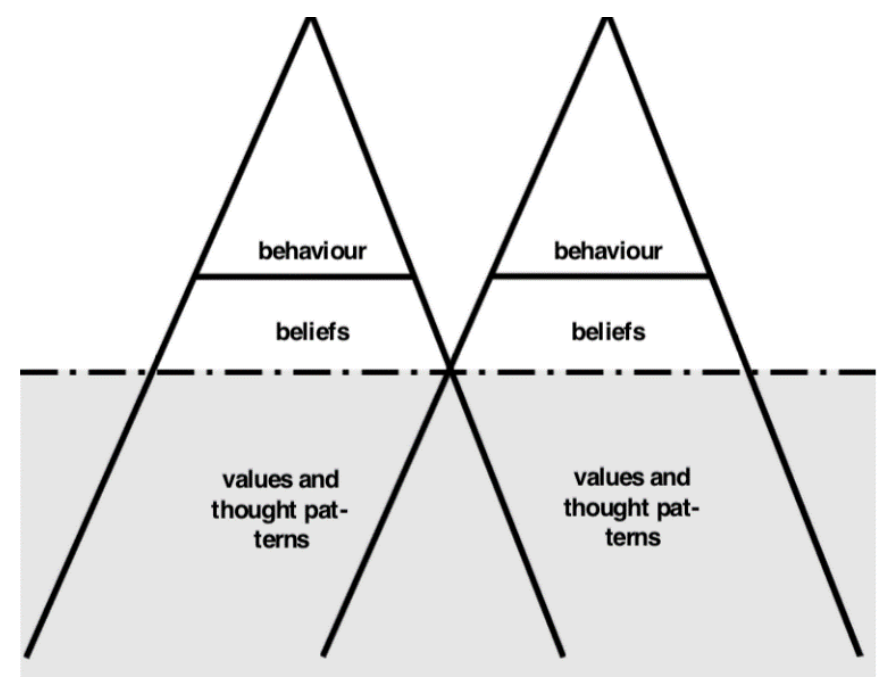

Figure 1. Weaver's Iceberg theory (Weaver, 1993, p. 135).

According to Byram (2008), with the help of the well-known metaphor of iceberg, the notion of culture can be grasped. In an iceberg, only a small proportion of the whole is visible, above the surface and in the metaphor the only small proportion is seen as culture, which is the part of consciousness towards culture such as folk traditions, food, sports and dress. However, below the waterline of the iceberg, there is much more of the culture, such as values and attitudes. It is much bigger yet invisible, which is the part of unconsciousness towards culture. Zelenková (2012) further suggests that the internal, hidden part of the culture is the most important since it governs our behavior. Therefore, what is above is about our actions and what is below is about our opinions and beliefs.

Moreover, it is not possible to separate language from culture; language learning and learning target cultures are in tandem not in isolation (Kramsch, 1993). Cultural competence means having the knowledge of another country's customs and beliefs and it is not separable in foreign language teaching (Thanasoulas, 2000). It has been globally accepted that in language learning, language and culture are inseparable and culture teaching is essential in language teaching (Kramsch, 1993). For this reason, learning a foreign language is an intercultural experience. According to Byram (2000), intercultural communicative competence (ICC) is the ability to be able to interact in an effective way with people from different cultures. ICC was firstly defined by Byram (1997) as a distinction between "the tourist and the sojourner". The tourist and the sojourner carry different characteristics, yet they are in contact. The tourist looks for an experience to enrich their life whereas the core is not affected by contacting different individuals who have different backgrounds. However, the sojourner affects the society with changing their beliefs, behaviors. As Sercu (2002) mentioned, the tourist tends to marvel at intriguing differences while the sojourner tends to turn intercultural encounters into relationships, therefore the sojourner can also be referred as interculturally competent individual. 
Deardorff (2006) mentions that ICC is the ability to interact not only effectively but also appropriately in intercultural situations with using attitudes, knowledge and skills. When ICC is integrated in language classrooms, learners have a chance to experience how to use the target language properly with building relationships and understanding individuals from different cultures. Thus, they can have a chance to gain an insider perspective of different cultures (Moeller \& Nugent, 2014). A person who has the knowledge of different cultures and the awareness of differences between cultures, also respects cultural differences and has the skills to communicate appropriately is considered as an interculturally competent individual (Lambert, 1993). Intercultural communicative competence turns a mono-cultural person into a multi-cultural person (Chen \& Starosta, 1996) and interculturally competent individuals are successful in building relationships in the foreign language with its speakers and also they are successful in negotiating how to communicate effectively in order to address the needs of the individuals. Therefore, gaining the intercultural communicative competence is not just about exchanges but it is about building relationships with the individuals from different worldviews (Byram, 1997).

According to Wiseman (2002), ICC is not innate; there are some preconditions such as knowledge, skills and motivation, or attitudes that help to develop intercultural competency (Byram, Gribkova, \& Starkey, 2002). Specifically, knowledge refers to the necessary information about other cultures. To be able to establish good relations with the members of other cultures, one needs to be aware of the differences of his/her own and the other cultures. Skills are about the performance of the behaviors. People who have the necessary knowledge are expected to behave appropriately in different cultures. However, having the necessary knowledge and skills is not enough to be interculturally competent. Motivation, or attitudes including feelings and perceptions have an impact on one's openness to engage in intercultural communication. Dislikes or prejudice influence people's decisions and behaviors. Therefore, all three components are crucial to be competent at intercultural communications which can be improved through education, experience and practice.

Finally, Alptekin (2002) proposed a new pedagogic model highlighting the importance of international and intercultural communication. Specifically, ICC should be developed among language learners providing them with linguistic and cultural behavior to enable them to communicate effectively with others. The learners should be aware of the differences among various languages and cultures and they should be able to cope with such differences (Hyde, 1998). Therefore, the instructional materials and activities should both local and international contexts that are relevant to learners' lives. Incorporating such pedagogies and instructional materials in English classrooms will help learners to become successful bilinguals and intercultural individuals who can function both in local and international contexts.

\section{LITERATURE REVIEW}

Developing ICC has become a shared goal among most researchers and educators in the field of language education. Learning a foreign language is not only knowing about how to use it for reading and speaking purposes, but it is also about knowing how to communicate with people who have different cultural identities. Considering the English education in Turkey, many scholars have supported the incorporation of ICC in language classrooms (Alptekin, 2002; Atay, Kurt, Çamlıbel, Ersin \& Kaslıoğlu, 2009; Devrim, 2006; Güven, 2015; Kahraman, 2008; Köroğlu, 2016).

One of the foremost studies on ICC was conducted by Alptekin (2002) who questioned the validity of the pedagogic model of the notion of communicative competence having its standardized native speaker norm. The research revealed the need for a new notion of communicative competence in order to involve local as well as international contexts of language use, and discourse participants of native-nonnative and nonnativenonnative so as to create successful bilinguals with intercultural knowledge. This would help with the realization of intercultural communicative competence.

Moreover, Atay et al. (2009) aimed to find out the attitudes of teachers towards the role of intercultural competence $(I C)$ in foreign language teaching. The data was obtained via questionnaires from 503 Turkish teachers of English from different regions in Turkey. The results revealed that the participating teachers had positive attitudes about the role of culture in foreign language education; however, they did not frequently carry out the mentioned practices relevant to culture teaching in their classroom practices.

Devrim (2006) aimed to reveal the opinions of the Turkish English language learners regarding the role of culture while learning English as a foreign language. To meet the objectives of this study, Devrim (2006) developed a questionnaire and administered it to 385 senior Anatolian High School students in five different high schools around Turkey. While the findings showed different opinions relevant to the inclusion of target language culture in English language classes, the students who shared positive views stated that language and culture cannot be separated from each other. Learning about the target language and its culture was 
perceived to be crucial to have enough information about native English speaking countries and compare it with Turkish culture. They also believed that interest and motivation towards learning English might increase by learning about the "target language culture."

Furthermore, Kahraman (2008) conducted a small scale research with Turkish university students (10 male and 12 female) studying at the English Language and Literature Department of a state university in Turkey. The study attempted to find out the views of learners on culture learning and to compare and contrast them with the existing beliefs about teaching culture in English classrooms. The data gathered from a Likert type scale showed that the participants were not sure whether they were culturally competent or not. They also stated that they did not have enough knowledge about the daily cultural habits of the target language. However, the students believed that culture learning is an indivisible part of language learning and they were willing to learn more about the target language culture.

Köroğlu (2016) looked for the language instructors' perceptions on ICC integration in English textbooks. Based on the findings collected from interviews and questionnaires administered to 68 language instructors, the majority of the participants agreed that cultural contents integration was not enough. Most participants stated that the textbook did not have sufficient content about students' own culture and they also thought that different cultures were not included in detail to prepare students for an intercultural encounter.

Güven (2015) attempted to find out the attitudes of Turkish learners of English attitudes towards ICC. The study examined whether any differences exist in terms of gender, reasons for learning English, proficiency levels in English, the medium of instruction in their departments and majors. The participants of the study were 508 students from seven different universities. The findings from the student questionnaires indicated that the participants had positive attitudes towards learning ICC. There was no significant difference relevant to gender, proficiency level and the medium of instruction in their department. The only difference was related to students' majors. The social sciences department students had more positive attitudes towards learning ICC rather than the students in natural sciences.

\section{Purpose}

Based on previous research on ICC, it is obvious that the acquisition of ICC is never done, never complete, yet it is a life- long activity. Hence, in language teaching, developing learners' intercultural communicative competence is essential (Robatjazi, 2008). Intercultural communicative competence is an area of study, which has been becoming more and more relevant in the ever-increasingly multicultural communities where we live. Specifically, incorporating ICC teaching into English language teaching is crucial to create a classroom environment that goes beyond different cultures of different individuals with different backgrounds. The present study, therefore, aims to investigate the perceptions of Turkish learners of English before and after incorporating ICC in their course. The study also attempts to find out the reflections of an English teacher about including ICC while teaching English. To meet these objectives, the following research questions were addressed:

1. What are the overall perceptions of the elementary level Turkish EFL learners before the implementation ICC?

2. What are the perceptions of the participating students about learning English after the integration of ICC?

3. What are the reflections of the teacher about the ICC driven module?

\section{Method}

\section{Research Model}

This study was designed as an action research which is considered to be very effective for teachers to chase their professional development inside the class (Burns \& Hood, 1995; Borg, 2002). Specifically, to meet the objectives of this study, an action research was used to investigate and understand the process of implementing ICC in an English course, find out the perceptions of students about learning English after being exposed to ICC and lastly, reveal the reflections of the English teacher using ICC in an English course. One of the instructors in this study was the exploratory researcher (Smith \& Robolledo, 2018) who attempted to investigate the process of using ICC and get in-depth information about teaching English through an ICCdriven module. The other research was an academician in the field of ELT who has carried out studies on the effectiveness of ICC in language education. 


\section{Setting and Participants}

The present study was carried out in a private English course in Istanbul, Turkey, The participants were 20 (12 female and 7 male) Turkish EFL learners. They were elementary (A1 level) students learning English for general purposes. In addition, the teacher was a 24 years old male with 5 years of teaching experience. He had his bachelor's degree and master's degree from the Department of English Language Teaching (ELT). To avoid reflexivity which refers to the "analytic attention to the researcher's role in qualitative research" (Gouldner, 1971a, p. 16), the researcher made regular diary entries during the study. In these entries, he reflected on his experiences about implementing ICC while teaching English in his classes. Apart from the teacher researcher, to foster the reflexivity, an external researcher also took part during the data collection process. The researcher was an academician in the field of English Language Teaching and was experienced in conducting research studies.

\section{Data Collection Tools}

For the purposes of this study, data was collected both quantitatively and qualitatively. The quantitative data came from pre- and post- ICC scale and the qualitative data was gathered from students' semi-structured interviews and teacher's reflective journal. Specifically, the ICC scale was adapted from Ergün's (2016) which aimed to find out the effects of ICC-integrated instruction in English language classrooms. The scale comprised of four subscales. The first subscale attempted to find out the students' attitudes towards ICC. The second subscale was about the knowledge of the participants about ICC whereas the third subscale aimed to identify the skills of students related to ICC. Finally, the fourth subscale tried to identify the actions of students about ICC. The whole scale included 28 items with seven items for each subscale. The items ranged from a five-point Likert type scale ranging from 1 (strongly disagree) to 5 (strongly agree). The scale was administered to 20 students enrolled in an elementary level English course.

Moreover, to complement the quantitative findings from the ICC scale, semi-structured interviews were carried out with randomly selected 10 students to explore their perceptions on learning English through ICC driven module. The interviews were conducted pre and post the incorporation of ICC in classroom practices. The participants were addressed four questions. The first question was posed to participants to find out their desire to interact and their interaction with individuals from different cultures, the second question was addressed to the participants to learn about their knowledge towards different cultures, their values and beliefs as well. In the third question, the participants were asked to whether they compare the differences between their own culture and different cultures or not. Finally, the last question was posed to the participants in order to find about their interest and confidence in interaction with individuals from different cultures. Finally, the teacher kept a journal reflecting on his practices about integrating ICC while teaching English for a total of 6 weeks. In the reflective journal, the teacher expressed his experiences and challenges about the ICC-driven module.

\section{Data Analysis}

In this study, the quantitative data collected by the means of an ICC scale and the descriptive statistics were estimated using SPSS (Statistical Package for the Social Sciences) 27.0. The descriptive statistics (means and standard deviations) and parametric analysis were used to test the means of normally distributed data. To compare the mean scores of the pre- and post- ICC scale, paired samples t-test was applied to find if there are statistically significant differences between the perceptions of the students after the incorporation of ICC. The level of significance for the statistical analyses was set at .05 .

To complement the quantitative data, qualitative data were collected by means of student semi-structured interviews and teacher reflective journals. The obtained data were analyzed through content analysis (Miles \& Huberman, 1994). The data was analyzed using open coding. After completing open coding, the main themes and sub-themes were determined under the labels related to the implementation of ICC-based lessons. To identify the inter-rater reliability degree, two experts identified the main themes from the codes from ELT (English Language Teaching) department. The inter-rater reliability was found to be .82 on the general themes apart from the different verbalizations of similar perceptions which showed a close agreement between the raters (McHugh, 2012). 


\section{Findings}

The present study aimed to investigate the perceptions of Turkish EFL students before and after being engaged in an ICC-based course. The study also attempted to find out the students' perceptions and the teacher's reflection about using ICC in an elementary level English course. The following section presents the obtained results.

\section{Perceptions of Students before the Incorporation of ICC}

To find out the overall perceptions of the participating students before the incorporation of ICC, data was gathered from an ICC scale and semi-structured interviews. The obtained findings of the pre-ICC scale are presented in the following table:

Table 1

Students' Perceptions of ICC

\begin{tabular}{lccc}
$\begin{array}{l}\text { Outcome } \\
(n=20)\end{array}$ & M & SD & $\begin{array}{c}95 \% \mathrm{Cl} \text { for } \\
\text { Mean Difference }\end{array}$ \\
\hline Attitude & 4.32 & 0.49 & $4.11,4.53$ \\
Knowledge & 4.09 & 0.52 & $3.86,4.32$ \\
Skill & 3.98 & 0.67 & $3.69,4.27$ \\
Action & 4.23 & 0.52 & $4.00,4.46$ \\
\hline
\end{tabular}

As shown in Table 1, the mean related to the ICC attitude was 4.32 and standard deviation was 0.49 ( $n=20$, $p<.05,95 \% \mathrm{Cl}$ for mean difference 4.11 to 4.53 ). The mean for the knowledge about ICC was 4.09 and standard deviation was 0.52 ( $n=20, p<.05,95 \% \mathrm{Cl}$ for mean difference 3.86 to 4.32 ). In addition, the mean regarding the skill in ICC was 3.98 and standard deviation was $0.67(n=20, p<.05,95 \% \mathrm{Cl}$ for mean difference 3.69 to 4.27). Finally, the mean for action in ICC was 4.23 and standard deviation was $0.52(n=20$, $p<.05,95 \% \mathrm{Cl}$ for mean difference 4.00 to 4.46$)$.

To complement these findings, semi-structured interviews were carried out with the participating students before they were exposed to the ICC-driven module. As a result of the content analysis, the findings were presented under four themes namely, deal for interaction, student awareness, cultural diversity and interacting with speakers of other cultures.

\section{Desire for Interaction}

Considering the desire of the participants about interacting with individuals from different cultures, the participants shared positive answers expressing that they have friends from different cultures and the enjoy interacting with them. The following excerpt supports this finding:

[...] I even have a Mexican friend. Since my English is not very good, sometimes we speak English or Turkish and I share the things that I learn here with him to practice. (S2, Pre-interview data, 20.01.2018)

\section{Student Awareness}

In an attempt to find out the awareness of students about different cultures, values and beliefs, the majority of the participants mentioned that they generally did not have much knowledge about different cultures. They also said that they were open to some cultures (not every culture in the world) as shown in the comment below: 
[...] I do not make an extra effort to learn a new culture, I am not curious. If I were, I would not be curious about their life-style. (S6, Pre-interview data, 20.01.2018)

[...] I am open to some cultures not every culture. (S3, Pre-interview data, 20.01.2018)

\section{Cultural Diversity}

As for the cultural diversity, the students were asked to compare the similarities and differences between their own culture and different cultures. Almost all of the participants said that it was not possible to compare the similarities and differences between other cultures and their own culture. They also argued that there were not such courses as expressed in these experts:

[...] I can't compare my culture with others. We have no such courses. (S5, Pre-interview data, 20.01.2018)

[...] I don't think we can compare our culture with others. I seems impossible. (S10, Pre-interview data, 20.01.2018)

\section{Interacting with Speakers of Other Cultures}

To find out the perceptions of the students about interacting with individuals from different cultures, all of the participants stressed that they enjoyed talking with speakers of other cultures as shown below:

[...] When I see a foreigner, I immediately try to speak with him. (S2, Pre-interview data, 20.01.2018)

[...] I am trying to improve my English. I find many friends from different cultures and I enjoy talking with them. (S6, Pre-interview data, 20.01.2018)

In brief, the findings of the interviews demonstrated that the participating students had positive perceptions about learning about different cultures and interacting with speakers from other cultures. However, they did not have much knowledge about different cultures as there was no such course in their program.

\section{Perceptions of Students after the Incorporation of ICC}

As for the perceptions of the students after ICC integration, a comparison of the pre- and post- ICC scale was conducted to see if there was any change. The following table reports the results:

Table 2

Findings for Pre- and Post- ICC Scale

\begin{tabular}{|c|c|c|c|c|c|c|c|}
\hline \multirow[b]{2}{*}{$\begin{array}{l}\text { Outcome } \\
(n=20)\end{array}$} & \multicolumn{2}{|c|}{ Pre-test } & \multicolumn{2}{|c|}{ Post-Test } & \multirow{2}{*}{$\begin{array}{l}95 \% \mathrm{Cl} \\
\text { for Mean } \\
\text { Difference }\end{array}$} & \multirow[b]{2}{*}{$t$} & \multirow[b]{2}{*}{$p$} \\
\hline & M & SD & M & SD & & & \\
\hline Attitude & 4.32 & 0.49 & 4.70 & 0.28 & $0.25,0.52$ & 5.81 & $.000 *$ \\
\hline Knowledge & 4.09 & 0.52 & 4.73 & 0.26 & $0.45,0.82$ & 7.16 & $.000^{*}$ \\
\hline Skill & 3.98 & 0.67 & 4.58 & 0.39 & $0.44,0.75$ & 7.91 & $.000^{*}$ \\
\hline Action & 4.23 & 0.52 & 4.75 & 0.30 & $0.35,0.71$ & 6.18 & $.000 *$ \\
\hline
\end{tabular}

As it can be seen from the $t$-test results, there were statistically significant differences in the students' perceptions the ICC-driven module. Specifically, the post-test results clearly showed that attitude, knowledge, skill and action scores increased compared to the pre-test results. On average, the attitude score 
was about .38 points higher, skill score was about .40 points higher, action score was about .52 points higher and knowledge score was about 64 points higher.

Similarly, post-semi-structured interviews were carried out with the students after the incorporation of ICC to find out if there was any change in the perceptions about ICC. After the content analysis, the findings were categorized under the same four themes: desire for interaction, student awareness, cultural diversity and interaction with speakers of other cultures which are summarized in the next part of this study.

\section{Desire for interaction}

As for the students' desire to interact with speakers of different cultures, the participants showed higher interest and confidence after being engaged in an ICC course. Specifically, they stated that after learning about different cultures, they wanted to learn more and felt confident while interacting with speakers of other cultures.

[...] After this course, I really have more interest and confidence in interacting with speakers of other cultures. (S8, Post-interview data, 04.03.2018)

[...] I have more interest and confidence about interacting with different speakers after I took this course. (S12, Post-interview data, 04.03.2018)

\section{Student Awareness}

As for the students' awareness about different cultures after the integration of ICC, almost all of them shared positive perceptions emphasizing that they learned many new things they did not know about different cultures. The following comments support this finding:

[...] In this course, I learned the things that I did not know before. I learned interesting things about different cultures. For example, I learned the cities that I did not know. (S13, Post-interview data, 04.03.2018)

[...] Thanks to this lesson, I learned new things about different cultures. I know more about them and I really enjoyed it. (S14, Post-interview data, 04.03.2018)

\section{Cultural Diversity}

The post-interview results revealed that after being exposed to ICC, the students started to compare their own culture with different cultures and they enjoyed it. Specifically, they learned more about wold cuisine and various national events as expressed below:

[...] I compare different cuisines with our own. Every food is reflecting its culture. (S2, Post-interview data, 04.03.2018)

[...] During the course, I have learned many national events of different countries. Some are similar to the ones in Turkey but others are very different. This is so fun. (S1, Post-interview data, 04.03.2018)

\section{Interaction with Speakers of Other Cultures}

As for the interaction of the students with individuals from different cultures after the ICC-based course, the participants expressed that their interaction increased particularly through social media. Considering this findings, two of the students said:

[...] I love interacting with individuals from different cultures. After this course, I found many new friends on the Internet. (S11, Post-interview data, 04.03.2018)

[...] I interacted with someone Indian on the Internet, usually they like Turkey and they would like to learn more about our country. It was fun. (S9, Post-interview data, 04.03.2018) 
To summarize, after being exposed to the ICC-integrated course, the students were more aware of different cultures as well as their own culture. They wanted to interact more with speakers from other cultures and showed higher interest as well as confidence. They learned many new things about different cultures and enjoyed this learning experience.

\section{Teacher's Reflections of integrating ICC in an English Course}

To gather in-depth understanding about teaching English using ICC, the teacher kept a reflective journal. In this section, the findings of the teacher's reflection were displayed under two major themes, motivation of the learners and difficulties encountered during the ICC course.

\section{Motivation of Learners}

Considering the motivation of students during the ICC course, the teacher stated that the students enjoyed the content by watching the videos on different cultures. They also actively participated in the lessons which attracted their attention as it can be seen from the following excerpts:

[...] The students were very engaged in the lesson. It was very obvious to see that they enjoyed watching videos about different cultures. (T, Journal Data. 25.02.2018)

[...] When I started to show the pictures of different cities one by one, the learners were very interested and all of them participated in the lesson. (T, Journal Data. 04.03.2018)

\section{Difficulties Encountered}

Apart from the positive reflections of the teacher about integrating ICC in the English course, there were some difficulties that the teacher experienced. The major difficulty was related to the speed of the videos, In other words, the videos were fast for some students and they had hard time to keep up with. It was also difficult to make students talk about some subjects they were not interested in. Considering these points, the following comments were made by the teacher:

[...] During the activity, I monitored the learners and I realized that some of the learners could not catch up the video. It was a bit fast. So I had to play the video once more. (T, Journal Data. 17.02.2018)

[...] Some of the students were not interested in the topics during the course. I could not make them speak about the topic. ( $T$, Journal Data. 27.01.2018)

To summarize, the reflections of the teacher showed that the students were interested in the ICC course and they were eager to learn new subjects. They enjoyed the videos about different cultures and participated in the course. However, some students had difficulty to follow the videos due to the speed and others were not willing to talk about the topics they were not interested in.

\section{Discussion}

As previously stated in this research, the major purpose of this study was to investigate the overall perceptions of Turkish EFL students about ICC. The obtained findings revealed that even though participating learners had some interactions with individuals from different cultures, they were not open to learn their values and beliefs of some cultures. The participants were comparing the differences in their own culture with different cultures which was in accordance with Devrim's (2006) study highlighting the importance of learning about the target language and comparing it with the speakers' own culture.

In addition, the results showed that the students did not have much knowledge and interest about different cultures, their values and beliefs before being exposed to the ICC-integrated course. These results were parallel to the study conducted by Kahraman (2008) which reported that language learners did not have enough knowledge about the daily cultural habits of the target language and they were willing to learn more about the target language culture. 
Furthermore, the study attempted reveal the perceptions of the participating students after the inclusion of ICC in their English course. The findings showed that there was a significant difference after the ICC-driven module. Specifically, there was an increase in the learners' attitude, knowledge, skill and action scores. Similarly, semi-structured interviews showed that the language learners increased their interaction with individuals from different cultures. The students became aware of various cultures and showed more interest. This finding was emphasize in Alptekin's (2002) study which aimed to develop intercultural communicative competence among EFL learners by raising their awareness so that they can feel comfortable in international and national cultures.

Finally, the teacher's reflections about incorporating ICC while teaching English were also examined in this study. The findings of the teacher's reflective journals demonstrated that the learners were interested and open to learn new subjects related to different cultures. The students enjoyed learning English in the ICCdriven module. These findings were in line with Atay et al. (2009) who empathized the role of integrating culture while teaching English to help learners to develop their intercultural competence.

\section{Pedagogical Implications}

The present study has some pedagogical implications to be taken into consideration. First, the findings of this present study demonstrated that the inclusion of ICC while teaching English has positive effects of the perceptions of the language learners as well as the reflections of their teacher about learning and teaching target language culture. Therefore, incorporating ICC in English courses will help learners to communicate effectively in local and international contexts. In addition, the findings of this study also showed that ICCbased using instructional materials and activities will have a positive influence on the language learners' attitude, knowledge, skill and action about different cultures.

\section{Limitations}

The present study has some limitations to be taken into consideration. First, the study was carried out in a private course in only one classroom. Adding a control group might have led more detailed and comparative findings. Besides, in this study, there were only 20 language learners and one English teacher. Conducting the study with a larger population could yield more reliable findings that can be generalized to different groups of learners. Additionally, the teacher of the implementation gave only his opinions about the experience of ICC-based lessons throughout the process of implementation in the reflective journals. Each ICC implementation lesson could have been observed by another teacher to received in-depth feedback. Moreover, due to the time constraints in the course, this present study lasted for only six weeks. Extending the implementation of the study over a longer period of time would lead in-depth and more detailed findings. Overall, since this study was designed as an action research, the findings of this study are only valid in this context with those participating learners. Therefore, the obtained findings should be taken as suggestive so that they can be addressed in further studies.

\section{Conclusion}

The present study contributes to the existing literature regarding the role of incorporating ICC in English language education. The findings revealed that the integration of ICC while teaching, learning and practicing English is particularly beneficial for language learners as it prepares them to understand and value other cultures as well as their own culture. It also prepares them to communicate with people from different cultures and share their experiences. Therefore, English language teachers should provide opportunities for students to reflect on and express their perceptions about target language culture which would help them to become successful communicators in international and intercultural contexts. 


\section{REFERENCES}

Alptekin, C. (2002). Towards intercultural communicative competence in ELT. ELT Journal, 56(1), 57-64.

Atay, D., Kurt, G., Çamlıbel, Z., Ersin, P., \& Kaslığlu, Ö. (2009).

The role of intercultural competence in foreign language teaching. Inonu University Journal of the Faculty of Education, 10(3), 123-135.

Byram, M. (1997). Teaching and assessing intercultural communicative competence. Clevedon, UK: Multilingual Matters.

Byram, M. (2000). Assessing intercultural competence in language teaching. Sprogforum, 18, 8-13.

Byram, M. (2008). Intercultural citizenship and foreign language education. Actes du Congrès International Année Européenne du Dialogue Interculturel: communiquer avec les langues-cultures, 122-132.,

Çetinavcı, U. R. (2012). Intercultural communicative competence in ELT. Procedia-Social and Behavioral Sciences, 46, 3445-3449.

Celce-Murcia, Marianne. 2007. Rethinking the role of communicative competence in language teaching. In E. Alcon Soler \& M. P. Safont Jordà (eds.), Intercultural language use and language learning. Spain: Springer, p. 41-57.

Chen, G., \& Starosta, W. J. (1996). Intercultural communication competence: A synthesis. Annals of the International Communication Association, 19(1), 353-383. doi:10.1080/23808985.1996.11678935

Creswell, J. W., \& Plano Clark, V. L. (2011). Designing and conducting mixed methods research (2nd ed.). Thousand Oaks, CA: Sage Publications, Inc.

culture teaching: an investigation of Spanish teachers' perceptions of the objectives of foreign language education. Intercultural Education, 15(1), 91-104.

Deardorff, D. K. (2006). Identification and assessment of intercultural competence as a student outcome of internationalization. Journal of Studies in International Education, 10(3), 241-266.

Devrim, D. Y. (2006). Students' opinions of the role of 'culture' in learning English as a foreign language (Unpublished master's thesis). Bogazici University, Istanbul.

Ergün. S. G. (2016). Investigating the effects of intercultural communicative competence integrated instruction through the development of intercultural communicative competence scales (Unpublished master's thesis). Bahçeşehir University, İstanbul, Turkey.

Gouldner, A. W. (1971a). Remembrance and renewal in sociology. For sociology: renewal and critique in sociology today. A. W. Goulder. New York, Basic Books.

Güven, S. (2015). EFL learners' attitudes towards learning intercultural communicative competence (Unpublished master's thesis). İhsan Doğramacı Bilkent University, Ankara, Turkey.

Hyde, M. (1998). Intercultural competence in English language education. Modern English Teacher, 7(2), 711. London.

Kahraman, A. (2008). A study of cultural aspects of English language with Turkish learners of English. Dumlupınar Üniversitesi Sosyal Bilimler Dergisi, 21, 1- 10.

Köroğlu, Z. Ç. (2016). Kültürlerarası iletişimsel yeterliliğin ders kitabına entegrasyonu üzerine bir araştırma; dil okutmanlarının bakış açıları. Kastamonu Üniversitesi Kastamonu Eğitim Dergisi, 24 (2), 619-632. Retrieved from http://dergipark.gov.tr/kefdergi/issue/22590/241309

Kramsch, C. (1993). Language study as boarder study: Experiencing difference. European Journal of Education, 28(3), 349-358.

Lambert, R. D. (1993). International education and international competence in the United States. European Journal of Education, 28(3), 309-325.

Langeland, A. S. D. (2013). Action research into the use of popular music: A goldmine worth exploring in the ELT secondary-school classroom? Nordic Journal of Modern Language Methodology, 2(1), 1-24.

McHugh, M. L. (2012). Interrater reliability: The kappa statistic. Biochemia Medica, 22(3), 276-282.

Miles, H. B., \& Huberman, A. M. (1994). Qualitative data analysis. Thousand Oaks, CA: Sage.

Moeller, A. J., \& Nugent, K. (2014). Building intercultural competence in the language classroom. In S. Dhonau (Ed.), 2014 report of the Central States Conference on the Teaching of Foreign Languages (pp. 118). Richmond, VA: Robert M. Terry.

of intercultural competence in foreign language teaching. Inonu University Journal of the Faculty of Education, 10(3), 123-135.

Robatjazi, M. A. (2008). Language education: Intercultural communicative competence and curriculum. Glossa, 3(2), 245-265.

Sercu, L. (2002). Autonomous learning and the acquisition of intercultural communicative competence: Some implications for course development. Language, Culture and Curriculum, 15(1), 61-74. doi:10.1080/07908310208666633 
Teddlie, C., \& Tashakkori, A. (2009). Foundations of mixed methods research: Integrating quantitative and qualitative approaches in the social and behavioral sciences. Sage.

Thanasoulas, D. (2000). The importance of teaching culture in the foreign language classroom (Unpublished master's thesis). University of Sussex, Brighton, UK.

Weaver, G. R. (1993). Understanding and coping with cross-cultural adjustment stress. In M. Paige (ed.), Education for the Intercultural Experience (pp. 137-167). Second Edition. Yarmouth, ME: Intercultural Press.

Zelenková, L. (2012). Developing intercultural communicative competence in learners of English (Unpublished master's thesis). Masaryk University, Brno, Czech Republic. Retrieved from https://is.muni.cz/th/199420/pedf_m/Diplomova_prace_-_Bc._Lenka_Zelenkova.pdf

Correspondence Inst. Gökalp GÜNEŞ gokalp.gunes.4@gmail.com

Assoc. Prof. Enisa MEDE enisamede@gmail.com 